\title{
Depth dependence of anisotropy of Earth's inner core
}

\author{
Xiaodong Song ${ }^{1}$ and Don V. Helmberger \\ Seismological Laboratory, California Institute of Technology, Pasadena
}

\begin{abstract}
Both body wave (PKP) travel times (Creager, 1992; Song and Helmberger, 1993a; McSweeney and Creager, 1993; Shearer, 1994) and fits to the splitting of core modes (Tromp, 1993) show general agreement that the top $300 \mathrm{~km}$ of inner core is very anisotropic. The anisotropy displays axial symmetry around the Earth's spin axis, with the polar direction $3 \%$ faster than the equatorial direction. One key problem now is the depth dependence of the inner core anisotropy. Here we extend our polar path studies to include both long-period and short-period modeling for the $P K P$ phases at ranges $120^{\circ}$ to $173^{\circ}$. Arrivals from the top of the inner core $(P K I K P)$ and reflections from the inner core boundary $(P K i K P)$ can be observed distinctly in short-period records at ranges $130^{\circ}$ to $140^{\circ}$ and as waveform distortions in the long-period records at ranges $130^{\circ}$ to $146^{\circ}$. These waveforms provide a new set of data for examining the topmost $150 \mathrm{~km}$ of the inner core, which is not well sampled by the previous body wave travel times. Record sections of waves traversing the inner core nearly parallel to the Earth's spin axis (polar paths) from three events, two beneath the South Sandwich Islands and one along the Macquarie Ridge, recorded at World Wide Standardized Seismograph Network, Canadian Network, and Long Range Seismic Measurements stations are analyzed. Our results suggest that the top $150 \mathrm{~km}$ of the inner core is only weakly anisotropic (less than 1\%), with strong evidence indicating that the top $60 \mathrm{~km}$ is not anisotropic at all.
\end{abstract}

\section{Introduction}

Recent findings show general agreement on the anisotropy of the inner core. Both body wave $P K P$ travel times [Creager, 1992; Song and Helmberger, 1993a; McSweeney and Creager, 1993; Shearer, 1994] and fits to the splitting of core modes by Tromp [1993] display axisymmetric anisotropy of around $3 \%$ with the fast direction parallel to the Earth's spin axis in the depth ranges of $150 \mathrm{~km}$ to $300 \mathrm{~km}$ into the inner core. Tromp's model displays a monotonic decrease of the anisotropy in $P$ wave velocity from the top of the inner core to the center of the Earth. The detailed resolution of the depth variation of the inner core anisotropy has yet to be investigated using body waves. Among many possible body wave phases $\left(P K P, P K S, S K P, P^{\prime} P^{\prime}\right.$, and $P K n K P$ ), the $P K P$ phases are the only phases that have been utilized to study the inner core anisotropy so far for their abundance and simple ray geometry. Figure 1 shows the ray paths of the various branches of $P K P$ phases.

\footnotetext{
${ }^{1}$ Now at Lamont-Doherty Earth Observatory of Columbia University, Palisades, New York.

Copyright 1995 by the American Geophysical Union.

Paper number 95JB00244.

$0148-0227 / 95 / 95 \mathrm{JB}-00244 \$ 05.00$
}

While the $P K P$ travel times along polar paths appear to be quite anomalous compared to those of equatorial paths, the sampling from the polar samples is rather sparse, as reported by Shearer [1994]. Most polar samples from the International Seismological Centre (ISC) data set are associated with paths originating at South Sandwich Islands. These events occur below $33 \mathrm{~km}$ and are probably the best documented in terms of travel time anomalies by Creager [1992], Song and Helmberger [1993a], and most recently Vinnik et al. [1994]. The recent studies by Song and Helmberger [1993a] and Vinnik et al. [1994] suggest that these anomalies persist at periods longer than $1 \mathrm{~s}$ and can be seen in broadband waveforms. These results are very significant in that such waveform data can be used to more fully understand the nature of the anisotropy as well as model shallow events where short-period picks of travel times alone are difficult to interpret. For example, as pointed out by Shearer [1994], the ISC times from events occurring along the Macquarie Ridge do not appear as anomalous as the South Sandwich events. That is, the ISC times from events occurring along the Macquarie Ridge do not support a strong anisotropy model. But since most of these events are strike-slip (occurring at transform faults) and most are rather small, we expect direct $P$ to be weak compared to $s P$; thus it becomes difficult to pick out the PKP triplication phases. In the distance ranges of $130^{\circ}$ to $146^{\circ}$, this problem is further complicated by the precursors to $P K P$ frequently observed. 


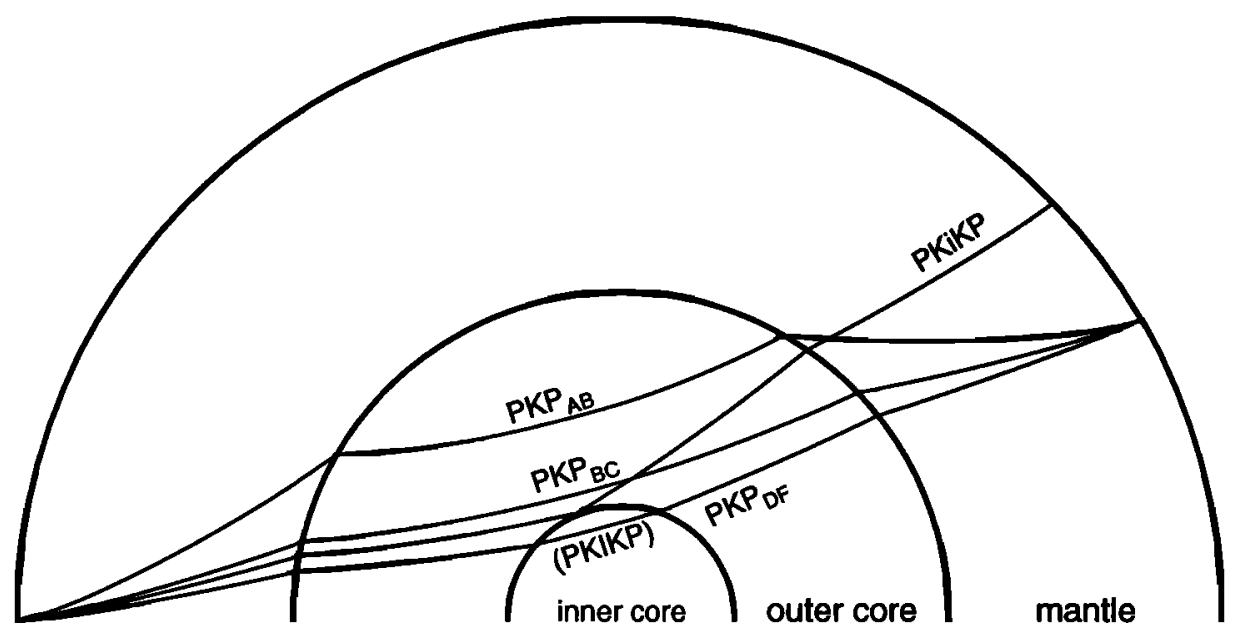

Figure 1. $P K P$ phases used to study the inner core anisotropy. In particular, $P K P$ waveforms at distance ranges from $130^{\circ}$ to $146^{\circ}$ are used to examine the anisotropy in the topmost part of the inner core.

In this report, we examine a few long-period and short-period record sections from events occurring beneath South Sandwich Islands and Macquarie Ridge to help establish the nature of the anisotropy both in depth distribution and spatial character. We concentrate on the topmost $150 \mathrm{~km}$ of the inner core. These depth ranges are not well sampled by the previous studies using $P K P-B C$ and $P K P-D F$ differential travel times and waveforms [Creager, 1992; Song and Helmberger, 1993a; McSweeney and Creager, 1993]. It appears that the detailed resolution of the anisotropy at the topmost part of the inner core comes from the waveform modeling of $P K P$ body waves before or around the caustic (from $130^{\circ}$ to $146^{\circ}$ ). At these distance ranges, arrivals from the top of the inner core, $P K I K P$ or $P K P-D F$, and reflections from the inner core boundary (ICB), PKiKP, can be observed distinctly in short-period records and have been used successfully to investigate velocity structure near the ICB in previous studies [Cummins and Johnson, 1988; Song and Helmberger, 1992]. In longperiod records, we rely on waveform distortions of these arrivals interacting with energy from the outer core. We followed the forward waveform modeling approach for the $P K P$ phases as described in details in our previous study [Song and Helmberger, 1992]. The synthetics were computed using generalized ray theory and the Cagniard-de Hoop method [Helmberger, 1983]. To account for extra attenuation in the inner core, a $t^{*}$ operator [Futterman, 1962; Carpenter, 1967] $\left(t^{*}=\int Q^{-1} d t\right.$ along the ray) is applied to the $D F$ branch.

Table 1 summarizes some useful parameters of $D F$ ray paths in the inner core. It is calculated for a surface focus using the Preliminary Reference Earth Model (PREM) [Dziewonski and Anderson, 1981]. Ranging 'from $120^{\circ}$ to $180^{\circ}$, the ray paths sample the top of the inner core to the center of the Earth. The sampling depths vary only slightly (within $20 \mathrm{~km}$ ) for two extremal focal depths at $0 \mathrm{~km}$ and $700 \mathrm{~km}$. The time residual of $D F$ for $3 \%$ axisymmetric anisotropy exceeds half a second at distance of $136^{\circ}$ for a ray angle from the equatorial plane in the inner core (hereinafter denoted as $\Phi$ ) of $63^{\circ}$, which can be readily resolved in shortperiod $D F$ and $P K i K P$ waveforms. If $3 \%$ anisotropy occurs throughout the inner core, the time residuals of $D F$ range from a few tenths of a second at $120^{\circ}$ to $6.5 \mathrm{~s}$ at $180^{\circ}$ for pure polar paths $\left(\Phi=90^{\circ}\right)$.

Included on the right of Table 1 are differential times of $P K P$ branches predicted from PREM along with those from a recent average $P$ velocity model of the Earth's core, PREM2 [Song and Helmberger, this issue]. The PREM2 model is modified from PREM to fit differential travel times, amplitude ratios, and waveforms of $P K P$ phases from scattered samples of nonpolar paths. It has a smaller velocity gradient at the base of the outer core and larger velocity jump at the inner core boundary, resulting larger differential travel times of $B C-D F$ and $C D-D F$. In addition, the $P$ velocity of PREM in the lowermost mantle is reduced to satisfy the mean of the observed $A B-D F$ times at distances from $147^{\circ}$ to $165^{\circ}$, which can serve as a baseline shift for $A B-D F$ differential times as tabulated in this table. Both models are used as references in detecting possible anomalies of the polar samples in this study. Many observations along nonpolar paths fit one of these models equally well. Thus the difference between these two models will serve as a guide to expected uncertainties along the polar paths.

\section{Waveform Modeling Results}

We examined three events in this study (Table 2), two occurring beneath the South Sandwich Islands (events 1 and 2) and one along the Macquarie Ridge (event 3). Event 3 was one of the events used by Häge [1983] to study the inner core from $P K P$ amplitudes. Stations were used from the World Wide Standardized Seismograph Network (WWSSN), the Canadian Network 
Table 1. Some Useful Parameters Related to PKP-DF for a Surface Focus

\begin{tabular}{|c|c|c|c|c|c|c|c|c|c|}
\hline \multirow[t]{3}{*}{$\Delta, \operatorname{deg}$} & \multirow[t]{3}{*}{$\Delta_{i c}, \operatorname{deg}$} & \multirow[t]{3}{*}{$T_{i c}, \mathrm{~s}$} & \multirow[t]{3}{*}{$Z_{\text {bot }}, \mathbf{k m}$} & \multicolumn{6}{|c|}{ Differential Times, 8} \\
\hline & & & & \multicolumn{3}{|c|}{ PREM } & \multicolumn{3}{|c|}{ PREM2 } \\
\hline & & & & $C D-D F$ & $B C-D F$ & $A B-D F$ & $C D-D F$ & $B C-D F$ & $A B-D F$ \\
\hline 120 & 4.0 & 7.8 & 0.8 & 0.05 & & & 0.10 & & \\
\hline 122 & 6.3 & 12.2 & 1.9 & 0.12 & & & 0.20 & & \\
\hline 124 & 8.7 & 16.8 & 3.7 & 0.21 & & & 0.32 & & \\
\hline 126 & 11.3 & 21.8 & 6.2 & 0.34 & & & 0.47 & & \\
\hline 128 & 14.0 & 27.1 & 9.5 & 0.49 & & & 0.66 & & \\
\hline 130 & 17.0 & 32.8 & 14.0 & 0.68 & & & 0.88 & & \\
\hline 132 & 20.3 & 39.0 & 19.9 & 0.90 & & & 1.13 & & \\
\hline 134 & 23.8 & 45.7 & 27.3 & 1.15 & & & 1.42 & & \\
\hline 136 & 27.7 & 53.0 & 37.0 & 1.45 & & & 1.76 & & \\
\hline 138 & 32.0 & 61.0 & 49.2 & 1.80 & & & 2.15 & & \\
\hline 140 & 36.8 & 69.8 & 64.8 & 2.20 & & & 2.59 & & \\
\hline 142 & 42.0 & 79.3 & 84.4 & & & & & & \\
\hline 144 & 47.8 & 89.6 & 108.7 & & & & & & \\
\hline 146 & 54.1 & 100.5 & 138.4 & & 0.99 & 1.44 & & 1.03 & 1.72 \\
\hline 148 & 60.8 & 111.8 & 173.9 & & 3.27 & 5.81 & & 3.31 & 6.22 \\
\hline 150 & 68.0 & 123.3 & 215.3 & & 5.07 & 10.61 & & 5.13 & 11.11 \\
\hline 152 & 75.4 & 134.8 & 262.7 & & 6.50 & 15.75 & & 6.72 & 16.36 \\
\hline 154 & 83.1 & 146.0 & 315.5 & & & 21.19 & & 8.23 & 21.91 \\
\hline 156 & 90.8 & 156.6 & 372.7 & & & 26.92 & & & 27.75 \\
\hline 158 & 98.6 & 166.5 & 434.1 & & & 32.93 & & & 33.87 \\
\hline 160 & 106.3 & 175.6 & 498.5 & & & 39.21 & & & 40.26 \\
\hline 162 & 114.0 & 183.9 & $\mathbf{5 6 5 . 6}$ & & & 45.74 & & & 46.91 \\
\hline 164 & 121.6 & 191.3 & 634.6 & & & 52.54 & & & 53.83 \\
\hline 166 & 129.1 & 197.7 & 705.2 & & & 59.59 & & & 61.00 \\
\hline 168 & 136.5 & 203.3 & 777.2 & & & 66.90 & & & 68.43 \\
\hline 170 & 143.9 & 208.0 & 850.0 & & & 74.45 & & & 76.11 \\
\hline 172 & 151.2 & 211.8 & 923.6 & & & 82.24 & & & 84.03 \\
\hline 174 & 158.4 & 214.7 & 997.6 & & & 90.28 & & & 92.20 \\
\hline 176 & 165.7 & 216.8 & 1072.0 & & & $\mathbf{9 8 . 5 5}$ & & & 100.60 \\
\hline 178 & 172.8 & 218.0 & 1146.7 & & & 107.06 & & & 109.25 \\
\hline 180 & 180.0 & 218.4 & 1221.5 & & & 115.80 & & & 118.12 \\
\hline
\end{tabular}

$\Delta$ is the epicentral distance; $\Delta_{i c}$ is the distance $D F$ travels in the inner core; $T_{i c}$ is the time $D F$ spends in the inner core and $Z_{\text {bot }}$ in the bottoming depth of the $D F$ ray path in the inner core. These parameters are calculated for a surface focus using the PREM model. The right side of the table compares the differential travel times of PKP phases for the PREM2 model and those for PREM.

(CAND) and the Long Range Seismic Measurements (LRSM). The analog seismograms were scanned and digitized. The digitization is accurate to a fraction of a second.

\section{South Sandwich Islands Events}

We selected two of the simplest events available from this region. The paths associated for event 1 are displayed in Figure 2. There are two distinct ray path groups from this event. One group contains polar paths to Canada and Alaska ( $\Phi$ ranging from $61^{\circ}$ to $72^{\circ}$ ); the other one contains nonpolar paths to Japan and South Korea ( $\Phi$ around $48^{\circ}$ ). The paths associated for event 2 are similar to the group to North America. The event is smaller than event 1 and is particularly well recorded by the LRSM network.

Figure 3 shows comparisons of observations (solid) for the latter nonpolar paths ( $\Phi$ around $48^{\circ}$ ) and synthetics (dashed) for the PREM2 model. The synthetics fit these observations reasonably well.

Figure 4 shows comparisons of two stations at close distances from a polar path (COL) and a nonpolar path (SHK) from event 1 . The traces are aligned with the $B C$ branch. The $D F$ branch for the polar path to COL $\left(\Phi=65^{\circ}\right)$, although at a smaller distance, arrives clearly earlier than the nonpolar path to SHK $\left(\Phi=47^{\circ}\right)$. This

Table 2. Events Used in This Study

\begin{tabular}{cccccrc}
\hline Event & Region & Date & Origin Time, UT & Epicenter & Depth, km & $\boldsymbol{m}_{b}$ \\
\hline 1 & South Sandwich & June 17 1967 & $0500: 12.0$ & $58.36^{\circ} \mathrm{S}, 26.83^{\circ} \mathrm{W}$ & 136 & 5.9 \\
2 & South Sandwich & Dec. 13 1965 & $1508: 27.2$ & $56.14^{\circ} \mathrm{S}, 27.76^{\circ} \mathrm{W}$ & 153 & 5.2 \\
3 & Macquarie Ridge & July 21 1977 & $1153: 22.3$ & $53.80^{\circ} \mathrm{S}, 158.80^{\circ} \mathrm{E}$ & 33 & 6.2 \\
\hline
\end{tabular}




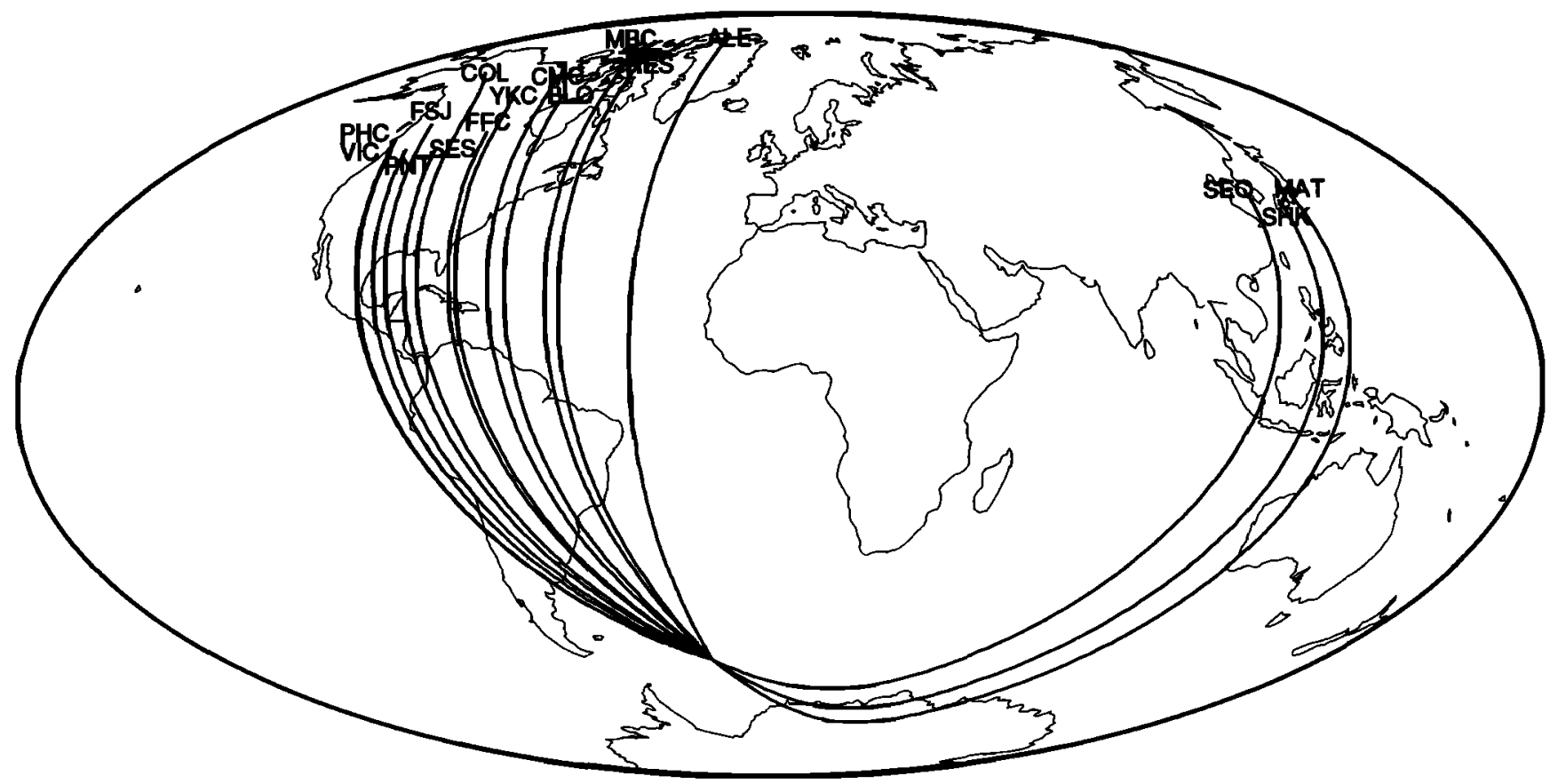

Figure 2. Ray paths of event 1 from the South Sandwich Islands. Paths of event 2 to North America stations are similar to those of event 1 .

is true in both long-period and short-period records. In the long-period channel, the $D F$ pulse of COL appears to be broadened. The anomalously early $D F$ arrivals for polar paths such as this example have been observed in previous studies and are most easily interpreted by axisymmetric inner core anisotropy of $3.5 \%$ based on samples from South Sandwich Islands to College, Alaska [Creager, 1992], or an average of $3 \%$ based on other more polar paths as well [Song and Helmberger, 1993a].

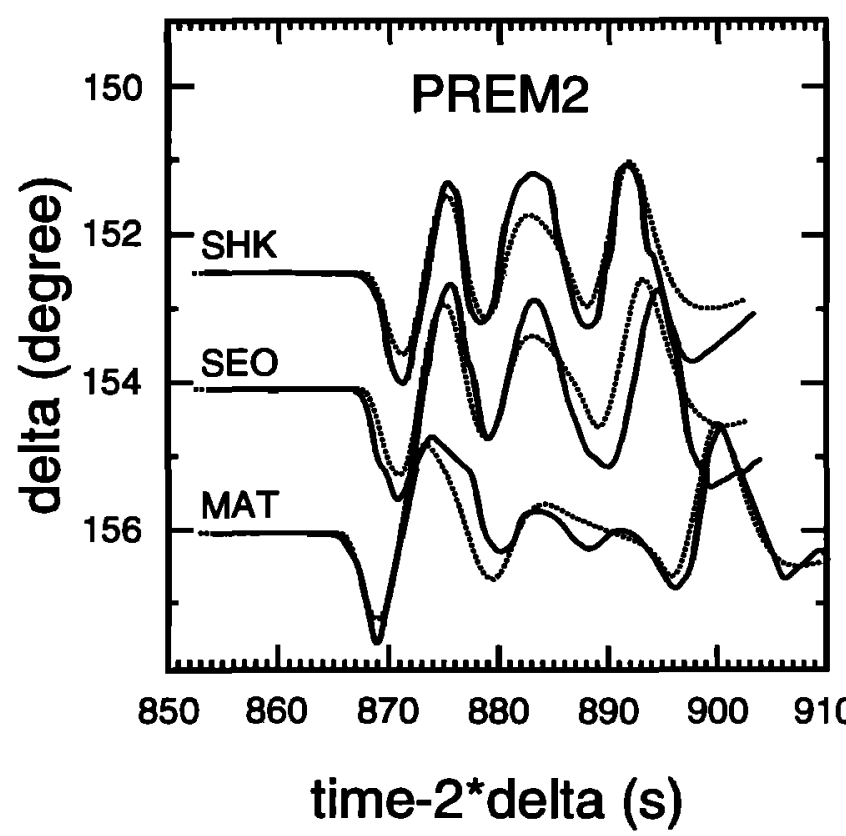

Figure 3. Comparisons of the observations (solid) from nonpolar paths of event 1 and synthetics (dotted) for PREM2 [Song and Helmberger, this issue].
These results appear to be compatible with the results from the recent revisit of ISC data [Shearer, 1994]. The question now is whether the anisotropy of this magnitude exists at the top few tens of kilometers of the inner core. To answer the question, we need to test the sensitivity of synthetic waveforms to various velocity distributions and examine how these synthetics compare with observations.

The depth dependence of the inner core anisotropy is explored by modeling the long-period PKP waveforms across the $P K P$ triplication, as shown in Figure 5. Solid lines are the observations for polar paths $(\Phi$ ranging from $61^{\circ}$ to $72^{\circ}$ ). Dotted lines are predictions from three test models. The synthetics were convolved with a simple trapezoid of $(1.8,1.8,1.8) \mathrm{s}$. The time function was determined from relatively simple pulses at smaller distances (FFC, PNT, BLC). Data are shifted to line up with the synthetics and are normalized to peak-to-peak amplitudes, i.e., only relative timing and amplitudes are examined. The left column shows that our average core model PREM2, which fits the nonpolar paths, does not fit the data for the COL record and records at distances approaching the $P K P$ caustic (RES, CMC, ALE). The $D F$ predictions from the inner core appear too late. The middle column shows synthetics for PREM2 model with a 3\% uniform increase of inner core $P$ velocity throughout the inner core. The misfits in waveforms before the caustic (RES, CMC, ALE) and near the caustic (MBC) are obvious. The model speeds up the $D F$ arrival so much that it becomes a very distinct arrival at CMC. Our current best fits are shown in the column on the right from a test model, PREM2_NS. This model has a $1 \%$ velocity increase at the top $200 \mathrm{~km}$ of the inner core and a $3 \%$ increase down below. The fits between $140^{\circ}$ and $146^{\circ}$ are significantly improved. The 


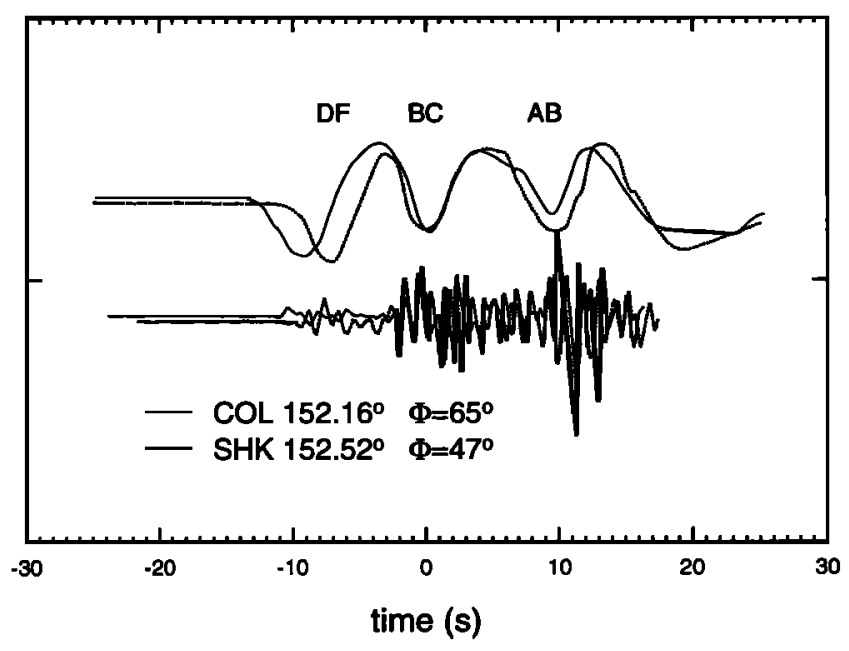

Figure 4. Comparisons of a polar path (COL) and a nonpolar path (SHK) at close distances from event 1. $\Phi$ is the angle of the $D F$ ray direction in the inner core from the equatorial plane, which is complimentary to the angle from the rotation axis. The top traces are long-period WWSSN records, and the bottom traces are short-period WWSSN records.

fits at distances smaller than $140^{\circ}$ are less discernible between models for these periods. More definite results rely on modeling of short-period records at these ranges, as discussed later. Nevertheless, this seismic section indicates the anisotropy at the very top of the inner core, perhaps the top $150 \mathrm{~km}$ (where the MBC ray bottoms), is weaker than that at greater depths, which we have seen in the $B C-D F$ differential times. The details of the model may vary, for instance, from a sharp discontinuity model to a smooth gradient model. It is of interest for further research to examine what happens in the hole between MBC and COL.

The short-period modeling results for event 2 are displayed in Figure 6. The data include short-period vertical components from both WWSSN and LRSM stations in North America. The station names (three letters for WWSSN, and four letters for LRSM) and the $\Phi$ angles are indicated. The synthetics are calculated using PREM. Dashed lines are the geometric travel time predictions of of $P K P$ phases from PREM. The empirical source functions for the synthetics are shown in Figure 7. The effective source function for LRSM records was obtained from the stack of the $P K i K P$ arrivals from three stations: WNSD, KNUT, and RGSD. The source function for WWSSN stations was taken directly from the direct $P$ arrival at LPS at $86.8^{\circ}$, which has a similar azimuth to those of the stations used. A differential $t^{*}=0.2 \mathrm{~s}$ was applied to the $P K I K P(D F)$ to account for inner core attenuation. This smaller $t^{*}$ value fits the $P K I K P+P K i K P$ waveforms significantly better than our earlier results of 0.35-0.4 s [Song and Helmberger, 1992, this issue] as well as $0.45 \mathrm{~s}$ in the recent study by Bhattacharyya et al. [1993], although the latter study show a great deal of scatter in $t^{*}$. We do not understand the discrepancy at present. To resolve it, many more samples are required.

In the bottom panel of Figure 6, the observation from COL is aligned in time and amplitude with respect to $B C$ arrivals in the synthetics. The $D F$ arrival from COL is $2.9 \mathrm{~s}$ earlier than PREM predictions due to inner core anisotropy at greater depths, which corresponds to an anisotropy larger than the average $3 \%$ for this particular example. On the other hand, the $A B$ arrival from COL is 1 s later than PREM predictions. This discrepancy can be explained by slowing down the $P$ wave velocity in the lowermost mantle. This is demonstrated by the long-period fit of the COL record in Figure 5 from PREM2, which slows down PREM in the lowermost mantle.

In the top panel of Figure 6, however, the PREM synthetics fit the observations rather well. In particular, individual pulses of $P K I K P$ and $P K i K P$ can be observed in the records of PGBC at $134.1^{\circ}$ and SIBC at $136.7^{\circ}$. Although these records have very similar ray angles with the spin axis as the COL record, the time separations between $P K I K P$ and $P K i K P$ for the records are well modeled by PREM predictions. Note that no clear precursors to $P K I K P$ are observed in any of the records. At CMC, however, we start to see diffraction from the $B$ caustic in both the data and the synthetic. The PKIKP waves bottom in the upper $60 \mathrm{~km}$ of the inner core for the distance ranges shown here. This suggests the absence of anisotropy at these depths of the inner core as sampled by the polar paths. Synthetic tests indicate that inner core anisotropy of $0.5 \%$ can be detected by our method. In fact, the fits of the PREM model to the observed PKIKP and PKiKP waveforms are better than those of PREM2, which has slightly faster velocity at the top of the inner core (by about $0.3 \%$ ) but slower velocity at the bottom of the outer core. The PREM2 model would predict $0.1-0.3 \mathrm{~s}$ larger separations between these two arrivals (see Table 1).

More polar samples, particularly in other parts of the Earth, are desired to investigate possible path variation. Nonetheless, the distinct differences at these two distance ranges for very similar paths from the same event argue strongly for only weak anisotropy, if any, in the upper $60 \mathrm{~km}$ of the inner core.

\section{Macquarie Ridge Event}

Unfortunately, the South Sandwich Islands is the only place in the southern hemisphere where polar paths from deep events can be obtained. Most of the other paths involve shallow ridge events which generally produce weak $P$ waves. Thus the scatter in the ISC $P K P$ data [Shearer, 1994] is particularly difficult to interpret. In this section, we consider one such event located on the the Macquarie Ridge (event 3). Figure 8 shows ray paths of the event to WWSSN and CAND stations. Both long-period and short-period records are collected at ranges of $121^{\circ}$ to $173^{\circ}$ and $\Phi$ angles up to $72^{\circ}$. In the following, the observations are divided up into a few distance ranges to examine the depth variation of the inner core anisotropy. 

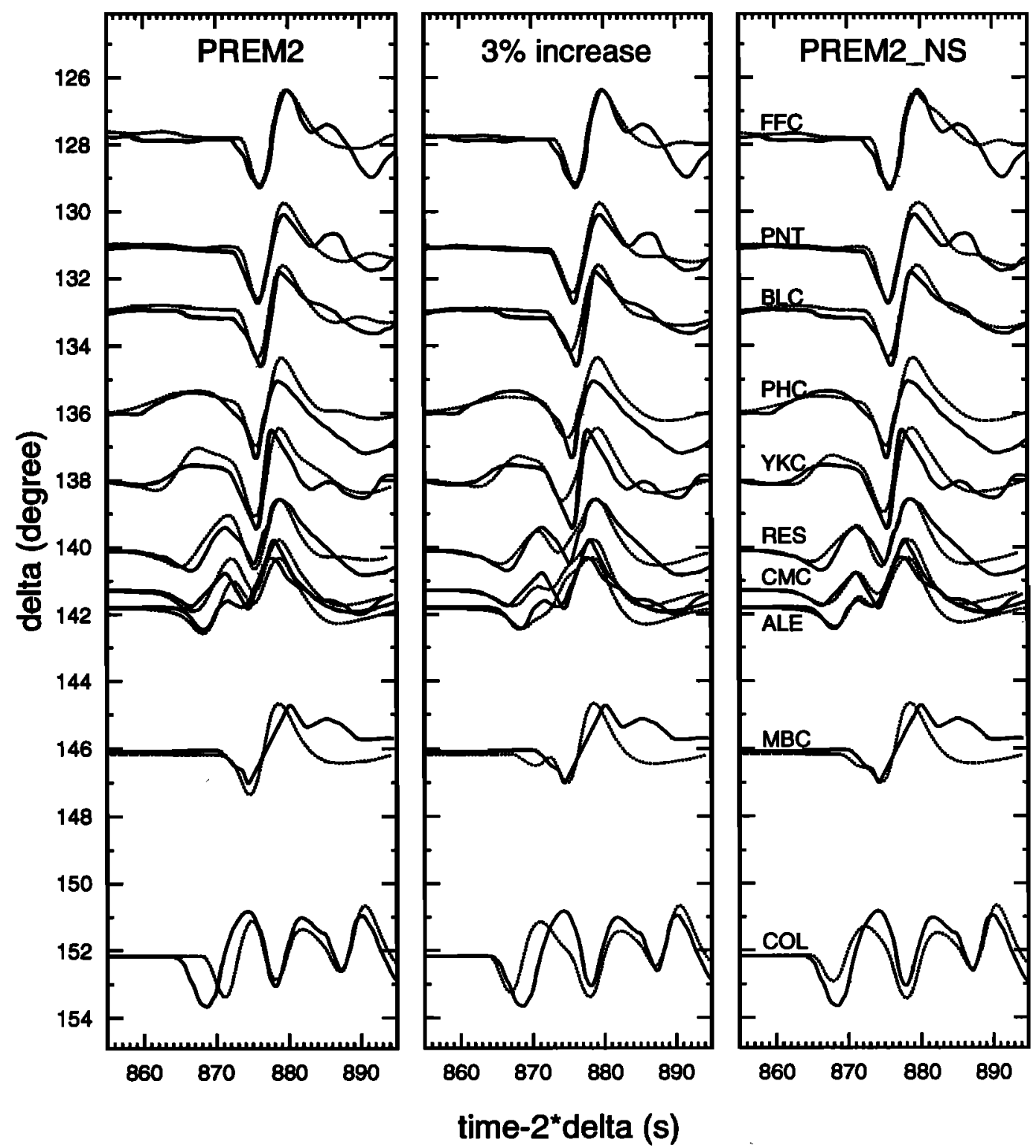

Figure 5. Comparisons of the observations (solid) for polar paths ( $\Phi$ ranging from $61^{\circ}$ to $72^{\circ}$ ) from event 1 and synthetics (dotted) for three test models.

Figure 9 shows short-period records from event 3 at distances before the $P K P$ caustic. In contrast to event 2 in Figure 6, clear precursors are observed in these records from $134^{\circ}$ to $140^{\circ}$, which are marked by a dashed line. These precursors have been interpreted as due to a discontinuity near the base of the outer core [Bolt, 1962, 1964], scattering from the $D^{\prime \prime}$ region [Haddon, 1972; Cleary and Haddon, 1972], and topographic relief of the CMB [Doornbos, 1988]. The Haddon and Cleary interpretation supposes that small scale features near the CMB allow ray-parameter variation, which brings some of the strong caustic energy at about $144^{\circ}$ to nearer distances along the extension of the $A B$ branch before the $D F$ arrivals. The shapes of these scatterers and their possible variation with location are still an area of active research [e.g., Bataille et al., 1990; Cormier, 1995]. The direct PKP arrivals are very weak and are best observed at distances smaller than $132^{\circ}$. The first geometric arrivals, $P K I K P$, are marked by a dashed line, which is calculated for PREM but shifted $-1.2 \mathrm{~s}$ to align with the first arrival at VIC. At the distances larger than $134^{\circ}$, these weak $P K P$ arrivals are in the wave trains of earlier $P K P$ precursory arrivals and are not easily identified. Because of the strong precursory arrivals and the weak emergent direct $P K P$ arrivals, it is difficult to model these records. Nonetheless, we performed a sensitivity test using stations EDM and INK, which have the weakest precursors. Figure 10 shows comparisons of the EDM and INK records (solid) and synthetics (dotted) from PREM2 and 3\% uniform increase of $P$ wave velocity of PREM2 in the inner core. An average differential $t^{*}$ of $0.35 \mathrm{~s}$ in PREM2 [Song and Helmberger, this issue] was applied to $D F$ arrivals for all the synthetics for event 3 . The empirical source function is obtained from the stack of VIC and PNT records. The synthetics for the model with $3 \%$ velocity increase 
Dec 13,1965 South Sandwich $(\mathrm{h}=153 \mathrm{~km})$

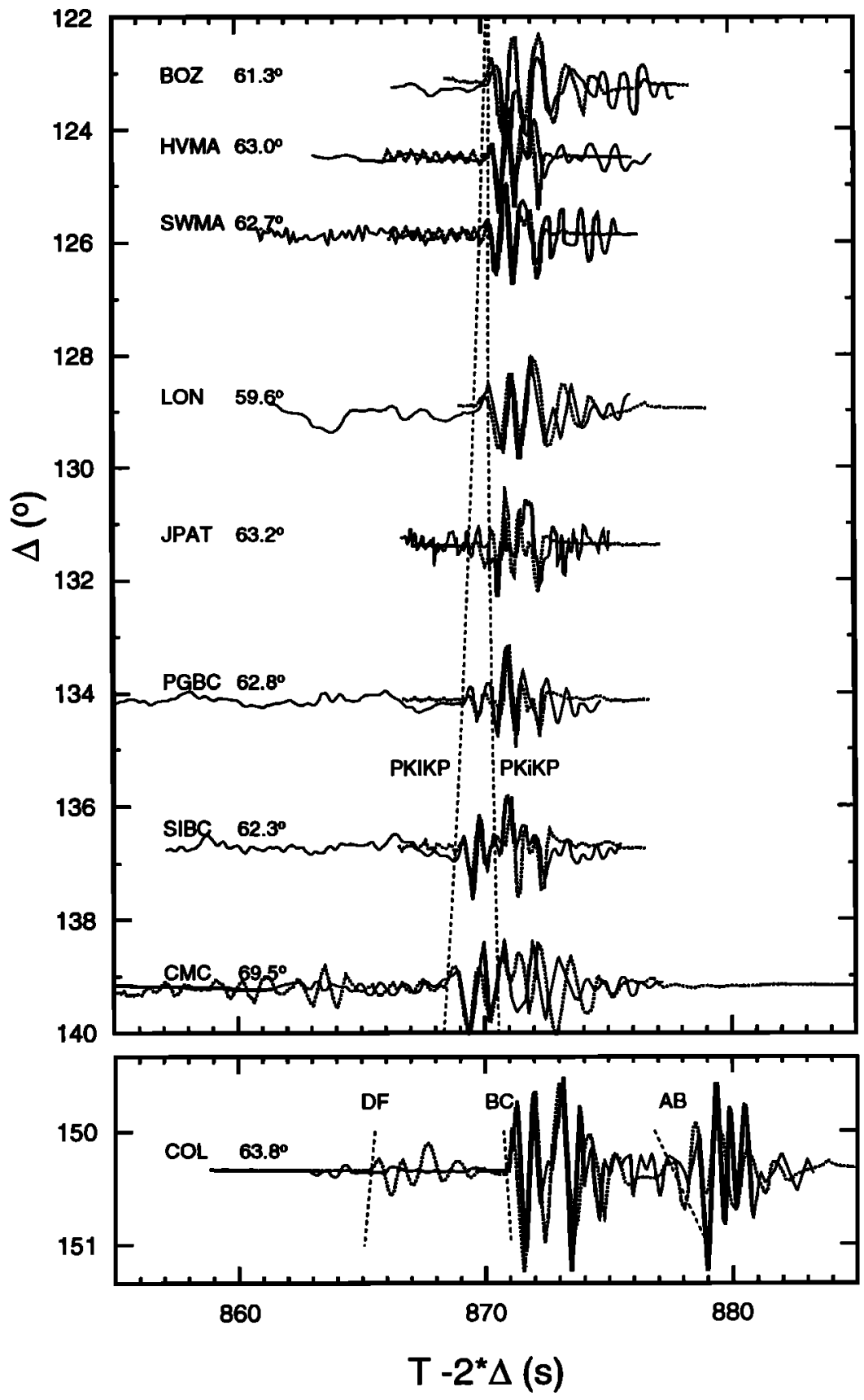

Figure 6. Comparisons of polar paths (solid) from event 2 and synthetics for PREM (dotted) [Dziewonski and Anderson, 1981], showing distinct differences at distances from $123^{\circ}$ to $139^{\circ}$ and distances around $150^{\circ}$. Dashed lines are the geometric travel time predictions of of $P K P$ phases from PREM.

show clear early arrivals compared to the synthetics for PREM2. However, there is no indication of these early arrivals in either record.

Figure 11 shows short-period records from event 3 a few degrees after the $P K P$ caustic, where the three branches of $P K P(D F, B C$, and $A B)$ are observed. The data (solid) are aligned with $B C$ arrivals in the synthetics (dotted). The $A B$ arrivals in the data generally agree with PREM2 predictions. But the discrepancies between the $D F$ arrivals from these polar paths and the synthetic predictions (PREM2) are clear. The differential time $B C-D F$ residuals are about $1.0 \mathrm{~s}$ to $1.5 \mathrm{~s}$ except SCH, which is most nonpolar of these records. The differential time anomalies, however, are only a half of what was previously observed for a similar orientation from South Sandwich Islands to College, Alaska, or about $70 \%$ of the average of the $B C-D F$ residuals from a larger data set [Song and Helmberger, 1993a] for 


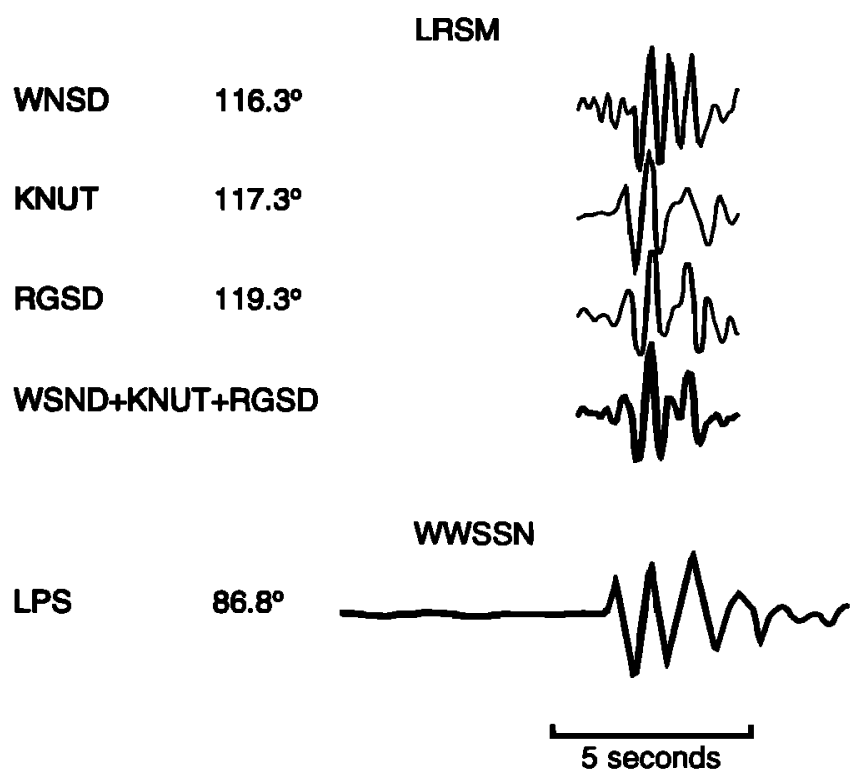

Figure 7. The effective source functions used for synthetics of event 2.

the same orientation. Note this path was examined in a recent study of ISC $D F$ travel times by Shearer [1994]. His data showed large scatter and he found no systematic anomalies for this path. Since this path provides a significant variation compared with numerous previous observations, it is important to analyze more reliable samples from this path for a more realistic model of inner core anisotropy. At this stage, it is difficult to know whether the variation in the $B C-D F$ differential times comes from lateral variation in the anisotropy amplitude or deviation of the anisotropy symmetry axis
[Su and Dziewonski, 1995] or more complex models of anisotropy than the simple axisymmetric model.

Figure 12 shows comparisons of data from event 3 and PREM2 synthetics at larger distances. The attenuation model and source function used are the same as above. Note that although VAL is not very polar, it shows a $1.5 \mathrm{~s}$ time anomaly, suggesting that the inner core anisotropy might persist into the center of the Earth. If all of the anomaly is attributed to the anisotropy in the inner core, the anisotropy is roughly $3 \%$ throughout the sampling depth (close to $1000 \mathrm{~km}$ ) assuming the axisymmetric anisotropy around the spin axis. There is large uncertainty in this estimate, however, because of large variations (around $2 \mathrm{~s}$ ) in $A B$ travel times largely due to lower mantle heterogeneity [Song and Helmberger, 1993b] and the fact that this sample is not very polar. A recent study by Vinnik et al. [1994] suggests that anisotropy as large as $3.5 \%$ persists into the center of the Earth from a more polar sample (from South Sandwich Islands to eastern Siberia).

Results of the waveform modeling of long-period records at the distances of event 3 before the PKP caustic are shown in Figure 13. The fits of the synthetics for PREM2 to the observations are fairly good. As before, the empirical source function is obtained from the stack of VIC and PNT records. The best polar path sample is from the station MBC near $140^{\circ}$, and it fits PREM2 well, indicating little need for anisotropy at this range. However, it becomes difficult to resolve this feature from the comparisons at smaller distance ranges, as pointed out in the discussion of Figure 6.

Figure 14 shows comparisons of synthetics for PREM2 and the data at distances beyond the $P K P$ caustic. The fits are generally consistent with the short-period results. The STJ record, however, shows an anomalously

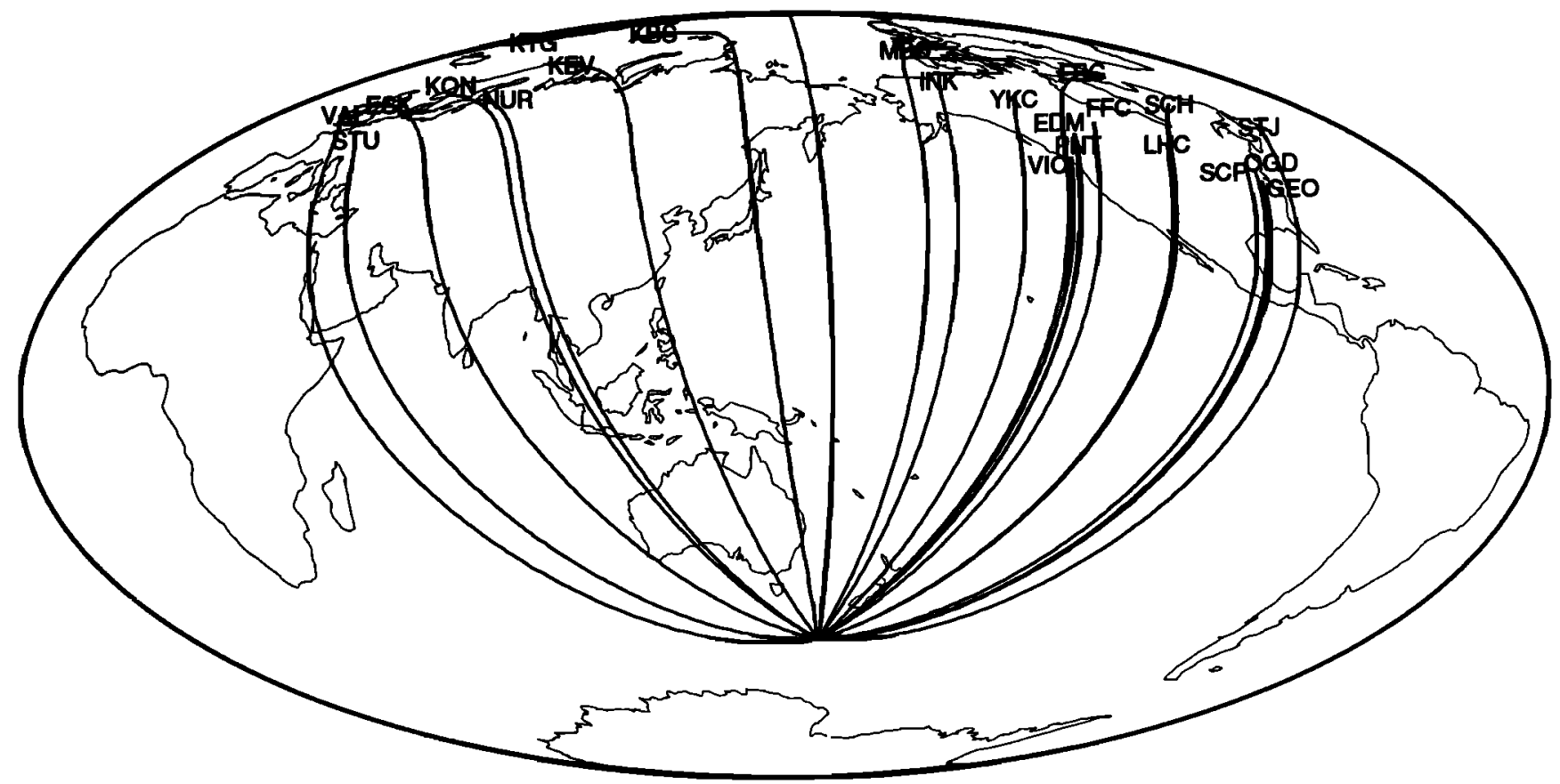

Figure 8. Ray paths from the Macquarie Ridge event (event 3). 
Jul 21, 1977 Macquarie Ridge

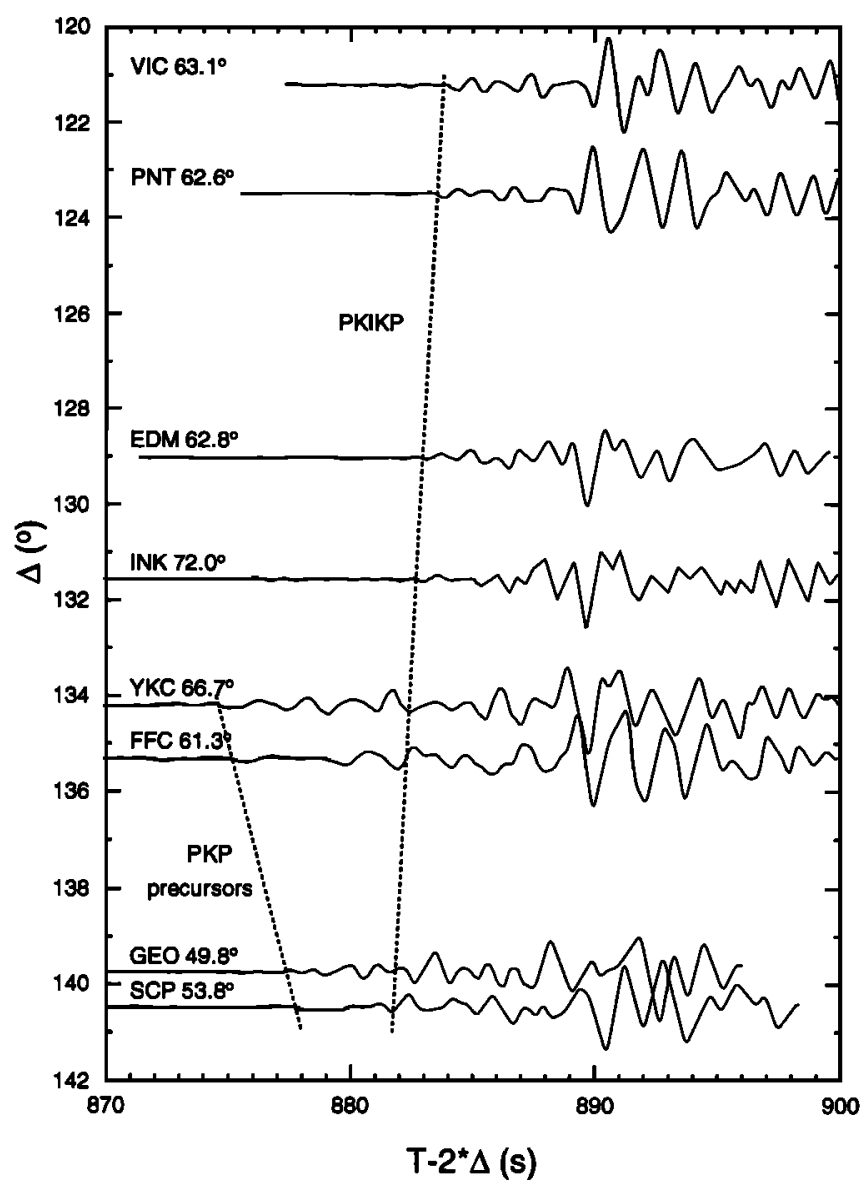

Figure 9. Short-period records from event 3 before $P K P$ caustic. Strong precursors and weak emergent direct $P K P$ arrivals make waveform modeling very difficult.

small $A B-D F$ time. Such anomalies are often observed [e.g., Song and Helmberger, this issue] and are possibly due to lateral variations in the lowermost mantle. This is coupled with the observation that STJ has quite a different ray path than a normal station such as STU at a neighboring distance (Figure 8). The time anomaly at station ESK is consistent with the anomaly observed in the short-period record VAL (Figure 12), which is compatible with the large anisotropy model into the center of the Earth.

\section{Discussion and Conclusion}

The main result of this study is that the anisotropy at the top $\sim 150 \mathrm{~km}$ of the inner core is weaker than that at greater depths. The data are well modeled by a zone of isotropy at the top of $\sim 60 \mathrm{~km}$ of the inner core. The improved synthetic fits to the long-period waveforms near the $P K P$ caustic from a distributed model of anisotropy at the top of the inner core (PREM2_NS) seems to suggest a transition from isotropy at the top $\sim 60 \mathrm{~km}$ to large anisotropy below $\sim 150 \mathrm{~km}$ of the inner core. Note that these numbers are estimated from bottoming depths of the sampling rays and are listed for descriptive purposes rather than definitive boundaries. It now raises the question of what physical process could cause such a structure. If the lattice preferred orientation of the hexagonally close-packed phase ( $\epsilon$-phase) of iron is responsible for the inner core anisotropy [e.g. Brown and McQueen, 1986; Anderson, 1986; Jeanloz and Wenk, 1988; Sayers, 1989; Karato, 1993], this could imply that some physical process prevents the formation of the lattice preferred orientation of $\epsilon$-iron near the inner core boundary.

This reduction of anisotropy at the very top of the inner core agrees with previous ISC studies, which suggest a small anisotropy of $1 \%$ at the top $50 \mathrm{~km}$ of the inner core from $D F$ travel times at distances from $132^{\circ}$ to $140^{\circ}$ [Shearer et al., 1988; Shearer 1994]. As Shearer $[1994$, p.19,654] concluded, the "anisotropy must be significantly weaker than $3 \%$ within the outer $\sim 50 \mathrm{~km}$ of the inner core." Furthermore, our study suggests

Jul 21, 1977 Macquarie Ridge

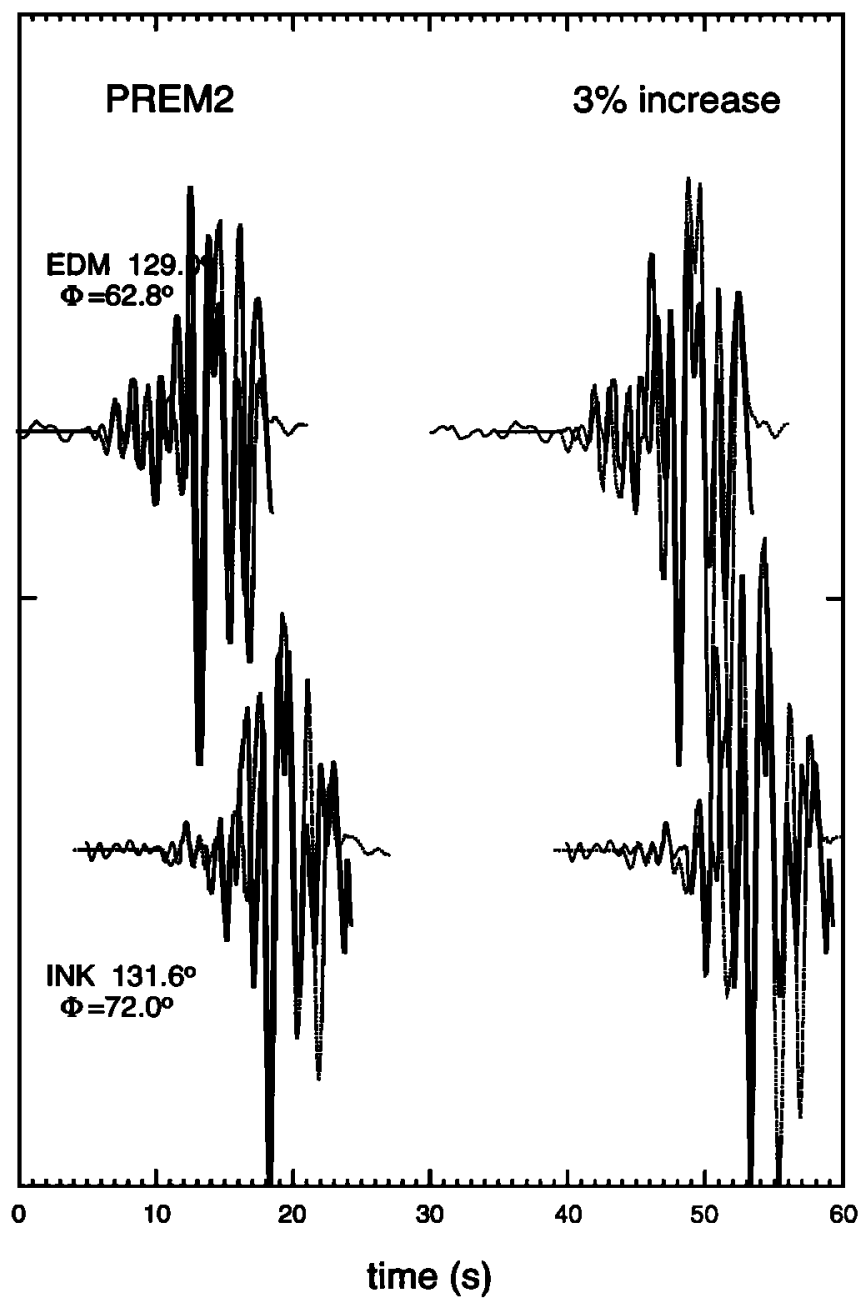

Figure 10. Comparisons of EDM and INK records from event 3 (solid) with synthetics (dotted) for PREM2 and 3\% uniform increase of $P$ wave velocity of PREM2 in the inner core. 
Jul 21, 1977 Macquarie Ridge

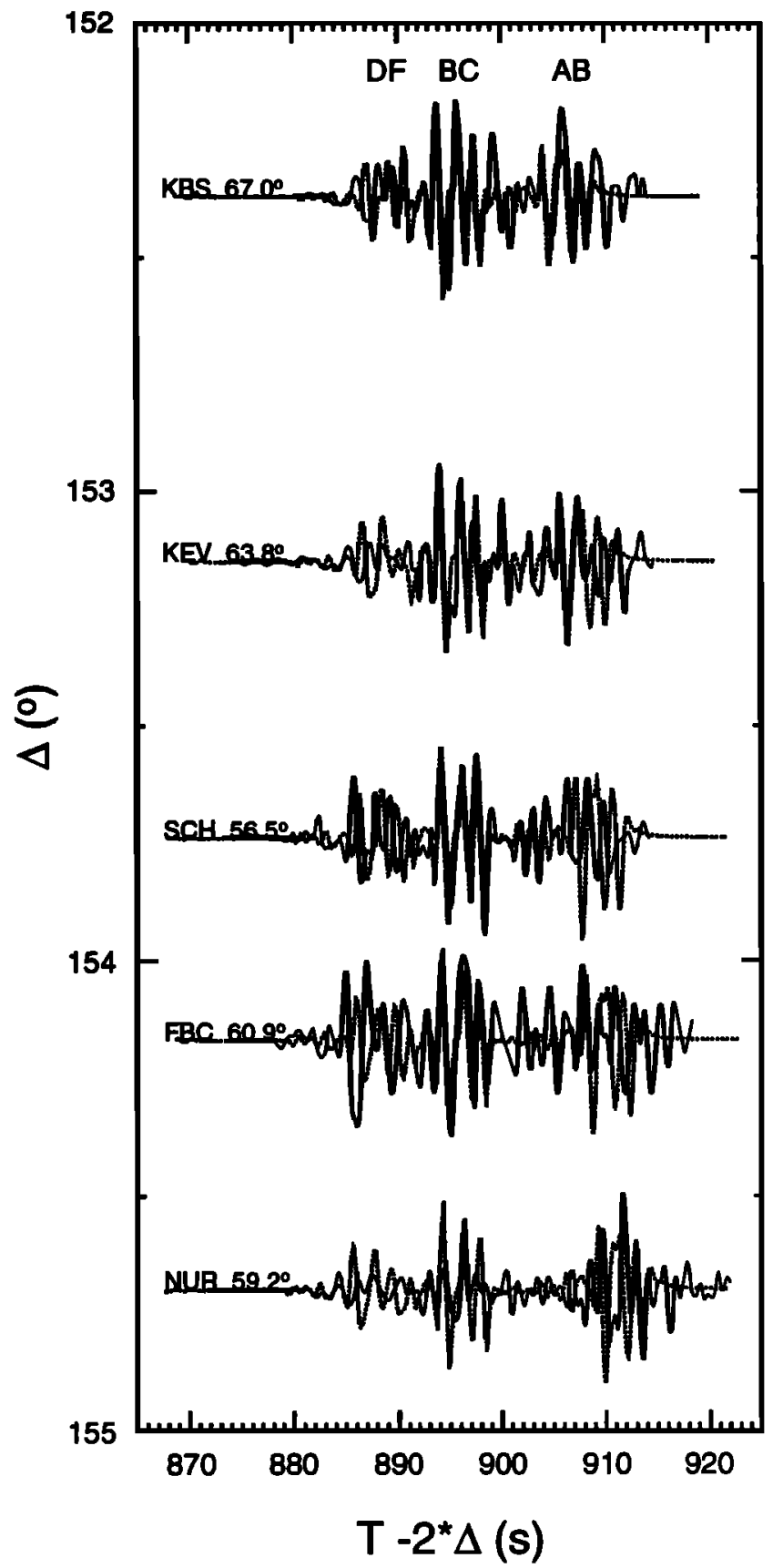

Figure 11. Comparisons of observations (solid) from event 3 and synthetics for PREM2 (dotted).

that the relatively weak anisotropy extends to depths of $\sim 150 \mathrm{~km}$, which are not sufficiently covered by ISC studies, since the PKP data in the neighboring distances $\left(140^{\circ}-150^{\circ}\right)$ are normally windowed out due to strong disturbances from the $B C$ branch and $P K P$ precursors. On the other hand, the possibility that the top $\sim 60 \mathrm{~km}$ is isotropic can not be ruled out from the ISC data, considering the uncertainties as presented by Shearer [1994].

The strength of anisotropy at the very top of the inner core has profound implications on our understanding of the splitting of normal modes. Some modes, such as ${ }_{11} S_{5}$ and ${ }_{16} S_{6}$, have very little energy in the inner core, and what little they have is sensitive only to the very top (J. Tromp, personal communication, 1994). Thus it becomes very difficult to fit the mode splitting if the anisotropy of the inner core is reduced significantly at depths down to $150 \mathrm{~km}$. This apparent conflict between body wave results and normal modes needs to be further addressed. 
Jul 21, 1977 Macquarie Ridge

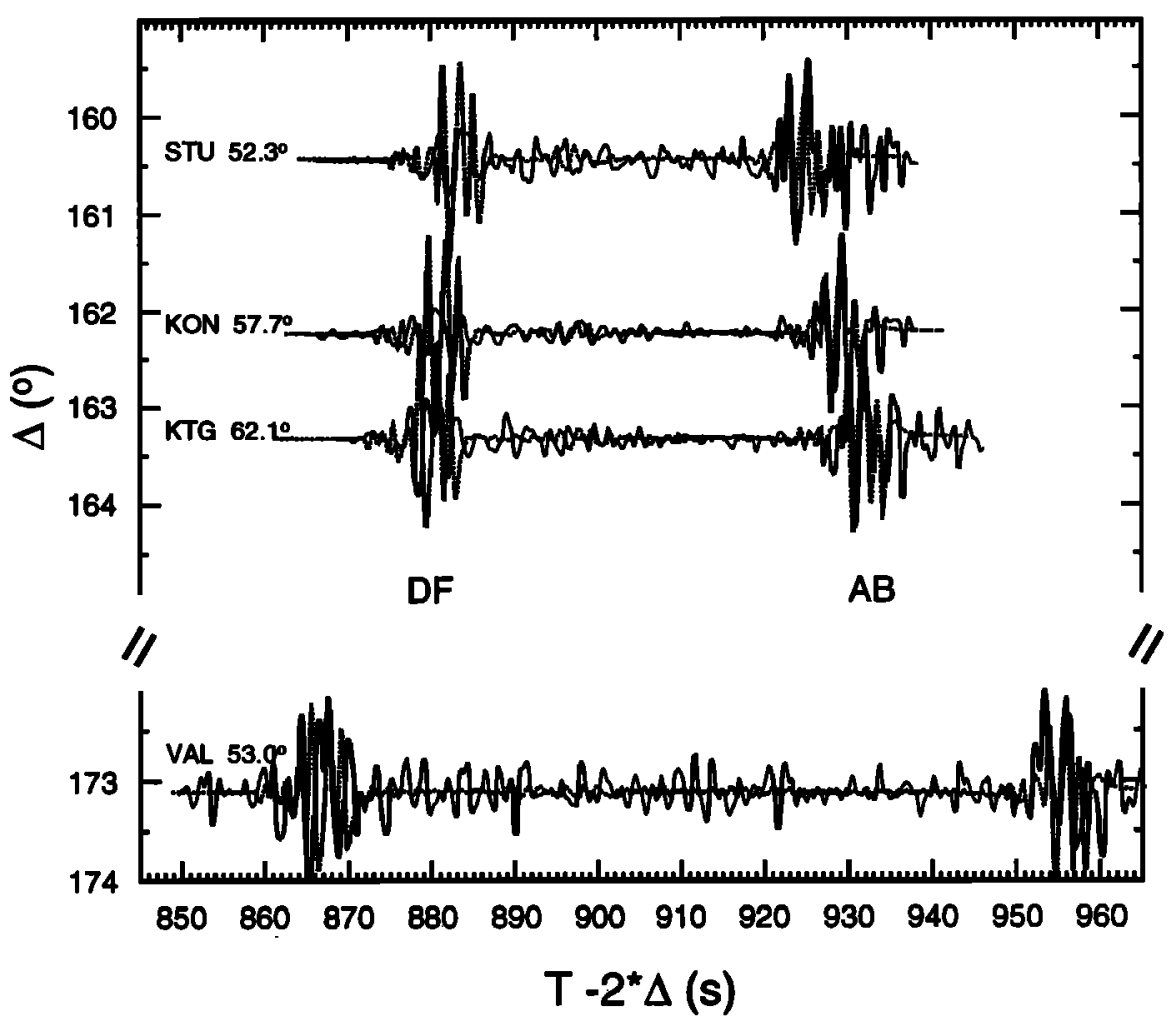

Figure 12. Same as Figure 11, but at larger distances.

Jul 21, 1977 Macquarie Ridge

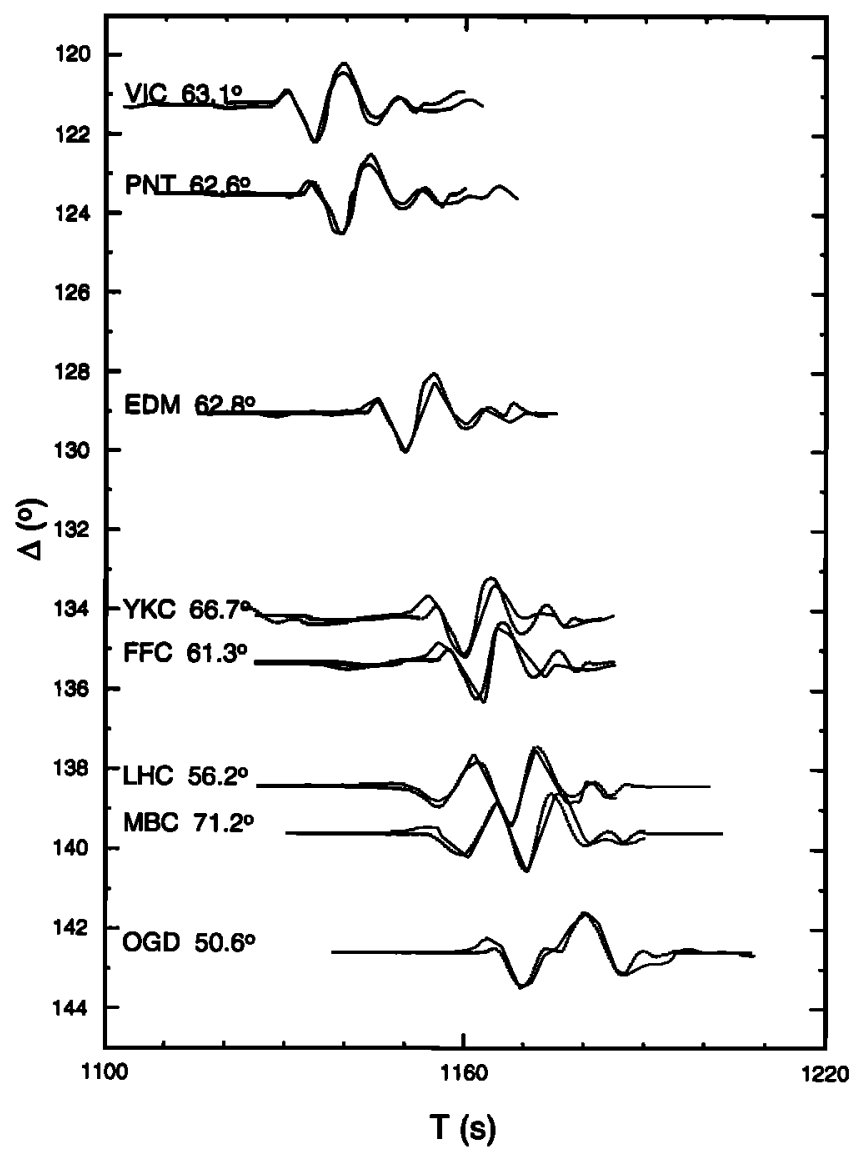

Figure 13. Comparisons of long-period records from event 3 and PREM2 synthetics before PKP caustic. The fits are fairly good.

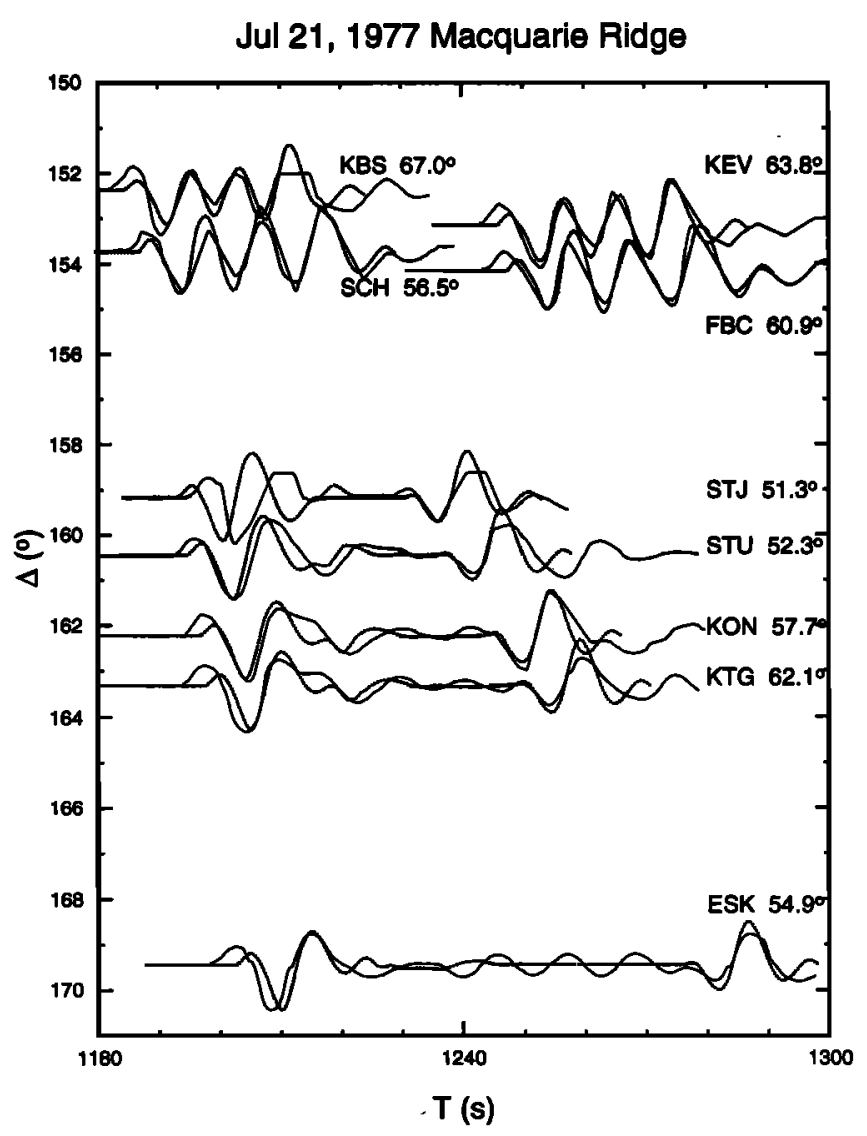

Figure 14. Comparisons of long-period records from event 3 and PREM2 synthetics after the $P K P$ caustic. 
Acknowledgments. We thank Peter Shearer for the preprint before publication and Jeroen Tromp from constructive discussions. We also thank Eddie Ganero and Don Anderson for helpful reviews. The reviews from Peter Shearer, George Helffrich, and Craig Bina greatly improved the manuscript. This research was supported by the National Science Foundation grant EAR-93-16441. Division of Geological and Planetary Sciences, California Institute of Technology, contribution 5426 .

\section{References}

Anderson, O.L., Properties of iron at the Earth's core conditions, Geophys. J. R. Astron. Soc., 84, 561-579, 1986.

Bataille, K., R.-S. Wu, and S.M. Flatté, Inhomogeneities near the core-mantle boundary evidenced from scattered waves: A review, PAGEOPH, 132, 151-173, 1990.

Bhattacharyya, J., P.M. Shearer, and G. Masters, Inner-core attenuation from short-period $P K P(B C)$ versus $P K P(D F)$ wave-forms, Geophys. J. Int., 114, 1-11, 1993.

Bolt, B., Gutenberg's early $P K P$ observations, Nature, 196, 122-124, 1962.

Bolt, B., The velocity of seismic waves near the Earth's center, Bull. Seismol. Soc. Am., 54, 191-208, 1964.

Brown, J.M, and R.G. McQueen, Phase-transitions, gruneisen-parameter, and elasticity for shocked iron between 77-GPA and 400-GPA, Geophys. J. R. Astron. Soc., 91, 7485-7494, 1986.

Carpenter, E.W., Teleseismic signals calculated for underground, underwater, and atmospheric explosions, Geophysics, 32, 17-32, 1967.

Cleary, J.R., and R.A.W. Haddon, Seismic wave scattering near the CMB: A new interpretation of precursors to $P K P$, Nature, 240, 549, 1972.

Cormier, V.F., Time domain modeling of PKIKP precursors for constraints on the heterogeneity in the lowermost mantle, Geophys. J. Int., in press, 1995.

Creager, K. C., Anisotropy of the inner core from differential travel times of the phases $P K P$ and $P K I K P$, Nature, 356, 309-314, 1992.

Cummins, P., and L. Johnson, Short-period body wave constraints on properties of the Earth's inner core boundary, J. Geophys. Res., 93, 9058-9074, 1988.

Doornbos, D.J., Multiple scattering by topographic relief with application to the core-mantle boundary, Geophys. $J ., 92,465-478,1988$.

Dziewonski, A.M., and D.L. Anderson, Preliminary reference Earth model, Phys. Earth Planet. Inter., 25, 297-356, 1981 .

Futterman, W., Dispersive body waves, J. Geophys. Res., 67, 5279-5291, 1962.

Haddon, R.A.W., Corrugations on the mantle core boundary or transition layers between inner and outer cores? (abstract), Eos Trans. $A G U, 53,600,1972$.
Häge, H., Velocity constraints for the inner core inferred from long-period PKP amplitudes, Phys. Earth Planet. Inter., 31, 171-185, 1983.

Helmberger, D.V., Theory and application of synthetic seismograms, in Earthquakes: Observation, Theory and Interpretation, International School of Physics "Enrico Fermi" Course LXXXV (Edited by H. Kanamori), pp. 174-222, North-Holland, New York, 1983.

Jeanloz, R., and H.R. Wenk, Convection and anisotropy of the inner core, Geophys. Res. Lett., 15, 72-75, 1988.

Karato, S., Inner core anisotropy due to the magnetic fieldinduced preferred orientation of iron, Science, 262, 1708$1711,1993$.

McSweeney, T.J., and K.C. Creager, Depth extent of innercore anisotropy from $P K P$ phases recorded at the Alaska Seismic Network (abstract), Eos Trans. AGU, 74(43), Fall Meeting Suppl., 407, 1993.

Sayers, C.M., Seismic anisotropy of the inner core, Geophys. Res. Lett., 16, 267-270, 1989.

Shearer, P.M., Constraints on inner core anisotropy from PKP(DF) travel-times, J. Geophys. Res., 99, 19,64719,659, 1994.

Shearer, P.M., K.M. Toy and J.A. Orcutt, Axi-symmetric Earth models and inner-core anisotropy, Nature, 333, 228232,1988 .

Song, X.D., and D.V. Helmberger, Velocity structure near the inner core boundary from waveform modeling, $J$. Geophys. Res., 97, 6573-6586, 1992.

Song, X.D., and D.V. Helmberger, Anisotropy of Earth's inner core, Geophys. Res. Lett, 20, 2591-2594, 1993a.

Song, X.D., and D.V. Helmberger, Effect of velocity structure in $\mathrm{D}^{\prime \prime}$ on $P K P$ phases Geophys. Res. Lett, 20, 285-288, $1993 b$.

Song, X.D., and D.V. Helmberger, A $P$ wave velocity model of the Earth's core, J. Geophys. Res., this issue.

$\mathrm{Su}$, W.J., and A.M. Dziewonski, Inner core anisotropy in three dimensions, J. Geophys. Res., in press, 1995.

Tromp, J., Support for anisotropy of the Earth's inner core from free oscillations, Nature, 366, 678-681, 1993.

Vinnik, L., B. Romanowicz, and L. Breger, Anisotropy in the center of the inner core Geophys. Res. Lett., 21, 1671$1674,1994$.

D. V. Helmberger, Seismological Laboratory, California. Institute of Technology, Pasadena, CA 91125. (email: helm@seismo.gps.caltech.edu)

X. D. Song, Lamont-Doherty Earth Observatory of Columbia University, Palisades, NY 10964. (email: xsong@ldeo.columbia.edu)

(Received July 8, 1994; revised December 31, 1994; accepted January 19, 1995.) 